\title{
Vitamin E Inhibition of the Effects of Hyperoxia on the Pulmonary Surfactant System of the Newborn Rabbit
}

\author{
JILL A. WARD AND ROBERT J. ROBERTS ${ }^{(40)}$ \\ Divisions of Neonatology and Clinical Pharmacology, Departments of Pediatrics and Pharmacology, The \\ University of Iowa, College of Medicine, Iowa City, Iowa, USA
}

\section{Summary}

The effects of vitamin $E$ on the neonatal surfactant system were studied in rabbits exposed to air or hyperoxia $(>95 \%)$ from birth through $48 \mathrm{~h}$ of life. Hyperoxia exposure resulted in lung lavage phospholipid content which reached only $74 \%$ of airexposed controls, and static pressure:volume observations of decreased maximum distensibility and altered compliance. Treatment with vitamin $\mathrm{E}(100 \mathrm{mg} / \mathrm{kg}$ of $d l$ - $\alpha$-tocopherol S.Q.) at 1 and $24 \mathrm{~h}$ of life was shown to completely abolish these effects of hyperoxia. Morphometrically determined alterations in epithelial cell composition and erythrocyte-contaminated air spaces resulting from hyperoxia exposure were also absent in pups treated with vitamin $E$. These findings suggest that early vitamin $E$ treatment in vitamin E-deprived newborns prevents hyperoxiaassociated compromise to the pulmonary surfactant system and selected other aspects of oxygen-induced lung injury in the neonate.

\section{Abbreviations}

HPLC, high pressure liquid chromatography

PC, phosphatidylcholine

PE, phosphatidylethanolamine

PG, phosphatidylglycerol

PI, phosphatidylinositol

PS, phosphatidylserine

Despite an appreciation of the toxic effects of oxygen on the lung, hyperoxia therapy remains a necessary mainstay for therapeutic support of infants born with inadequate lung function. Hyperoxia treatment has been associated with the development of bronchopulmonary dysplasia in the chronically exposed newborn infant (23). Furthermore, we have recently demonstrated that hyperoxia compromises the maturing pulmonary surfactant system of the neonatal rabbit, implicating a role of acute hyperoxia toxicity in the course of neonatal respiratory distress syndrome (36).

The use of vitamin $\mathrm{E}$ to prevent hyperoxia-associated lung injury has been investigated clinically, with conflicting reports on its benefit in newborns with respiratory distress syndrome (1, $12,13,21,29)$. Studies utilizing animal models have added to this controversy. Some investigators have reported a protective effect by vitamin $E$ against certain morphologic and antioxidant enzyme alterations and loss in pulmonary gas exchange resulting from hyperoxia exposure $(8,37)$. Other studies, however, have observed no effect of vitamin $E$ on hyperoxia-associated changes in morphology and endothelial integrity $(8,16)$. Because of the proported antioxidant activity of vitamin $E$ and the known lipid composition of surfactant (18), vitamin E may provide protection to the pulmonary surfactant system. In spite of the large interest in vitamin $E$, its influence in specifically reducing the vulnerability of the surfactant system to oxidant injury has not been previously studied.

In view of the rapid changes which occur in the pulmonary surfactant system with birth and the onset of breathing and the known susceptibility of the newborn lung to hyperoxia toxicity, the effects of vitamin $E$ on the pulmonary surfactant system in rabbits exposed to air or hyperoxia were evaluated from birth through $48 \mathrm{~h}$ of life.

\section{MATERIALS AND METHODS}

Gestationally timed pregnant rabbits were obtained from a local supplier (Morrison Rabbitry, West Branch, IA). Day of mating was considered day zero. At $31 \mathrm{~d}$ gestation (full-term) pups were delivered by Caesarian section under $2.5 \%$ halothane:oxygen anesthesia in order to minimize fetal asphyxia. Newly delivered animals were randomly divided into four groups for air or hyperoxic exposure with treatment at 1 and $24 \mathrm{~h}$ of life, with either vitamin E ( $d l-\alpha$-tocopherol, free alcohol) 100 $\mathrm{mg} / \mathrm{kg}$ subcutaneously, or vehicle placebo. The pups were housed immediately after birth in $4 \mathrm{~L}$ chambers maintained at $36^{\circ} \mathrm{C}, 80 \%$ humidity. Continuous use of a $3-\mu$ filter in-line with the gas supply, and ultraviolet exposure of chambers before use were utilized for bacterial control. Gas flow, either air or $100 \%$ oxygen, was $4 \mathrm{~L} / \mathrm{min}$. Oxygen concentration was monitored in air and oxygen exposure chambers with an OM-14 oxygen analyzer (Beckman Instruments, Inc, Schiller Park, IL) maintaining a $21 \%$ concentration of oxygen for the air chamber, and greater than $95 \%$ for the hyperoxia chamber. All pups were given a $5 \%$ dextrose/saline solution by subcutaneous injection $(1 \mathrm{ml} / 30 \mathrm{~g}$ body weight) at $6 \mathrm{~h}$ of life. Gavage feedings were carried out every $24 \mathrm{~h}$ using a specially formulated Purina newborn rabbit nutrient solution (35). The nutrient solution contained $1.7 \mu \mathrm{g} /$ $\mathrm{ml}$ vitamin $\mathrm{E}$ ( $d l-\alpha$-tocopherol) which provided a total nutritional contribution of $0.28 \mathrm{mg} / \mathrm{kg}$ of vitamin $\mathrm{E}$ over the 48 -h experimental time period. At $48 \mathrm{~h}$ the animals were given a lethal dose of sodium pentobarbital and placed in $100 \%$ oxygen to metabolically degas the lungs.

Lungs from individual pups were used either for pressure:volume determination of lung compliance followed by lavage fluid collection and subsequent surfactant analysis, or were processed for light level microscopic evaluation. For pressure:volume determination of static compliance, the trachea was cannulated immediately upon sacrifice of the pup. The lungs were inflated at approximately $10 \mathrm{~cm} \mathrm{H}_{2} \mathrm{O} / \mathrm{min}$ using a U-tube water manometer. At given pressure intervals, volumes were recorded for construction of the pressure:volume curve. Maxi- 
mum volume at $30 \mathrm{~cm} \mathrm{H}_{2} \mathrm{O}$ pressure was maintained for $5 \mathrm{~min}$ before deflation was performed. A drop in pressure of more than $10 \mathrm{~cm} \mathrm{H}_{2} \mathrm{O}$ during this time was considered to be the result of an air leak, and the animal was excluded from analysis. Subsequent to this 5 -min period the lungs were reinflated to $30 \mathrm{~cm}$ $\mathrm{H}_{2} \mathrm{O}$ pressure. This volume was recorded as $\mathrm{V}_{30}$. Deflation was performed at the same rate, with volumes again recorded at given pressure intervals. Volumes were corrected for air compression in the system and expressed as percentage of volume at $30 \mathrm{~cm}$ $\mathrm{H}_{2} \mathrm{O}$ pressure. Calculations of pressure at three different volumes provided a quantitative index for comparing compliance in air and hyperoxia-exposed animals: $30 \% \mathrm{~V}_{30}$ on inspiration and $80 \% \mathrm{~V}_{30}, 30 \% \mathrm{~V}_{30}$ on expiration. The $\mathrm{V}_{30}$ measurement was selected as an indicator of maximal distensibility of lung for comparison between the two treatment groups.

Subsequent to pressure:volume determinations, the animals were placed head-down on an inclined plane to facilitate passive gravitational fluid collection and lavaged five times via a tracheal cannula with normal saline. The volume used was $80 \%$ of $V_{30}$. To qualify for inclusion in lavage analysis, total fluid collected from lungs of each animal had to equal at least $85 \%$ of the volume introduced. This technique has been shown to provide for recovery of $90 \%$ of extracellular surfactant phospholipid (27). Lavage fluid for each individual animal was pooled and centrifuged at $150 \mathrm{~g}$ for $10 \mathrm{~min}$. The resulting supernatant was frozen at $-20^{\circ} \mathrm{C}$ until analyzed.

All lavage samples were analyzed in duplicate. Chloroform was redistilled just before use, and methanol was HPLC grade. One-milliliter aliquots of lavage samples were extracted with chloroform:methanol $(2: 1 \mathrm{v} / \mathrm{v})$ after the procedure of Bligh and Dyer (4). The chloroform layer was recovered and dried under $\mathrm{N}_{2}$ at $45^{\circ} \mathrm{C}$. Separation of individual phospholipids was accomplished using thin layer chromatography on Whatman LK5D plates (Whatman Inc, Clifton, NJ) with the solvent system chloroform:methanol:acetic acid:water (50:35:4:2), as developed by Rooney et al. (27). This system provided for the separation of PC, PS + PI, PE, and PG. These individual phospholipids were identified using standards obtained from Sigma Chemical Company, St Louis, MO. Phospholipids were visualized with an iodine vapor system. Individual phospholipids were quantitated by determining the phosphorous content using the method of Bartlett (3). Addition of standard phospholipids to lavage samples indicated $91 \%$ recovery of phospholipid with these procedures.

After completing the lavage procedure, the wet lung weight was determined and lung weight was obtained on the left lung after drying in an oven at $55^{\circ} \mathrm{C}$ for at least $6 \mathrm{~d}$. The right lung portion was used for protein and DNA analysis. The right lung tissue was homogenized in a $10 \mathrm{x}$ volume ice cold potassium phosphate buffer (pH 7.4) for 30 s using a Polytron (Brinkmann Inst, Westbury, NY) on high speed. DNA content was determined using a method described by Richards (25). Protein was analyzed by a modified Lowry method $(2,30)$. In randomly selected pups from each treatment group, lung tissue homogenates were analyzed for vitamin E content by HPLC, using modified methods of Westberg et al. (38). Contamination of lung tissue by Vitamin $E$ contained in blood was found to be negligable and, therefore, the lung was not perfused before homogenation for vitamin E determination. Approximately $200 \mathrm{mg}$ of lung tissue from individual rabbits was extracted, dried under $\mathrm{N}_{2}$, and redissolved in $0.14 \mathrm{ml} \mathrm{n}$-hexane for injection of $0.1 \mathrm{ml}$ onto a u-Bondapak- $\mathrm{NH}_{2}$ column \#84040 (Waters Associates, Inc, Milford, MA). Ethanol (0.8\%) in n-hexane was used as the mobile phase with a flow of $2.0 \mathrm{ml} / \mathrm{min}$. Spectrophotometric detection was achieved by use of a Spectroflow Monitor SF 770 and a GM 770 Monochrometer (Schoeffel Instruments Division, Kratos, Inc, Westwood, NY) at $280 \mathrm{~nm}$. A standard curve of $0.2-2.0 \mu \mathrm{g} \alpha$-tocopherol was employed and found to give a linear response by peak height analysis. Extraction of standard $d l-\alpha-$ tocopherol added to homogenate showed this procedure to provide essentially complete recovery of $\alpha$-tocopherol from tissue homogenates.
The lungs of animals used for morphologic evaluation were inflated by tracheal infusion of a solution of cacodylate-buffered glutaraldehyde (4\% solution, $\mathrm{pH} \mathrm{7.3)} \mathrm{at} \mathrm{a} \mathrm{pressure} \mathrm{of} 20 \mathrm{~cm} \mathrm{H}_{2} \mathrm{O}$ with the chest cavity open. Fixation by inflation at a controlled pressure was performed to eliminate possible artifactual differences due to postmortem absorption atelectasis of animals breathing $100 \%$ oxygen. Tracheas were then ligated, and the lungs were excised and immersed in fixative for $24 \mathrm{~h}$ at $4^{\circ} \mathrm{C}$. The left lung was used for sectioning in the following manner: a full cross-section was cut from lower portion of the lower lobe, and five blocks approximately $4 \mathrm{~mm}^{2}$ were randomly taken from the upper portion of the lower lobe and from the upper lobe. The tissues were postfixed in phosphate-buffered osmium tetroxide (2\%) for 1-2 h, washed in distilled water, en bloc stained with uranyl acetate, dehydrated in graded methanols and embedded in Epon 812. Thin sections $(1-2 \mu)$ were stained with toluidine blue for light microscopy.

Light level morphometric studies were performed at a magnification of $\times 400$ with an AO microscope equipped with a 25square eyepiece grid. While avoiding large vessels and airways, five random fields per section were selected, and line intersections were scored as to their presence over interstitial tissue, air space, or capillary space. At $\times 100$ magnification a quantitation of air spaces containing erythrocytes relative to clear airspaces was performed using the same grid to count representative airspaces under or next to line intersections. Relative numbers of Type I, Type II, and undifferentiated epithelial cells were determined at $\times 100$ magnification using identification criteria outlined by Khosla et al. (17). Cells lying under grid intersections were counted using fields from each of five sections to achieve a total of 150-200 cells/animal. Slides were coded so that counting was achieved without knowledge of treatment received by animals. Statistical analysis of all parameters was performed using the Student's $t$ test for grouped comparisons.

Vitamin E and placebo vehicle were contributed by HoffmanLaRoche Inc, Nutley, NJ.

\section{RESULTS}

Body weights, dry lung:body weight ratios, and lung DNA:protein ratios are reported in Table 1. All three parameters, reflecting whole body and lung growth, were unaffected by $48 \mathrm{~h}$ of hyperoxia exposure or vitamin $\mathrm{E}$ treatment in comparison with air-exposed, placebo-treated controls. In addition, survival and gross indications of well-being were not different in any treatment group. Lung $\alpha$-tocopherol content (Table 2) reflected doses administered, with an approximate 50 -fold increase in the groups treated with vitamin $\mathrm{E}$. There was no effect of hyperoxia exposure on lung vitamin $E$ content, which agrees with the findings by Bucher and Roberts (7) in the newborn rat.

Determinations of maximum distensibility $\left(V_{30}\right)$ from pressure:volume analysis are shown in Figure 1. A decrease in $V_{30}$ was observed in animals exposed to hyperoxia + placebo, as compared with air-exposed, placebo-treated controls. Vitamin $\mathrm{E}$ treatment prevented this decrease in maximum distensibility in animals exposed to hyperoxia, resulting in $V_{30}$ values of pups in hyperoxia + vitamin $E$ which were similar to those of air-exposed pups. In air-exposed animals, vitamin $E$ treatment did not appear to have any effect on $V_{30}$.

Figure 2 illustrates means of actual pressure:volume curves expressed as percentage of maximum distensibility $\left(V_{30}\right)$. In pups treated with placebo and exposed to hyperoxia, there was an apparent right shift of the inflation curve and a slight left shift of the deflation curve. Figure 3 shows a quantitative comparison of three inflation/deflation points calculated from individual pressure:volume curves. Hyperoxia exposure lead to an increase in the pressure necessary to inflate the lungs to $30 \%$ of $V_{30}\left(P_{30 \mathrm{i}}\right)$. Decreases in pressures on deflation at $80 \%$ of $V_{30}$ and $30 \%$ of $V_{30}\left(P_{80 d}, P_{30 d}\right)$, (Figs. 3B and $\left.C\right)$ were also observed in pups in the hyperoxia + placebo treatment group. With vitamin $E$ treatment these pressure:volume changes associated with hyperoxia were abolished. 
Table 1. Effects of hyperoxia and vitamin E treatment on body weight, dry lung weight: body weight ratios, lung DNA content, and lung protein: DNA ratios in newborn rabbits*

\begin{tabular}{|c|c|c|c|c|}
\hline & $\begin{array}{c}\text { Air + placebo } \\
\quad(n=7)\end{array}$ & $\begin{array}{c}\text { Air + vitamin E } \\
(n=14) \\
\end{array}$ & $\begin{array}{c}\text { Hyperoxia }+ \text { placebo } \\
(n=9)\end{array}$ & $\begin{array}{l}\text { Hyperoxia + vitamin } \mathrm{E} \\
(n=10)\end{array}$ \\
\hline Body weight (g) & $50.9 \pm 6.2$ & $53.7 \pm 2.7$ & $48.2 \pm 4.5$ & $55.1 \pm 3.3$ \\
\hline Dry lung weight: body weight & $3.0 \pm 0.1$ & $3.2 \pm 0.1$ & $3.3 \pm 0.1$ & $3.2 \pm 0.2$ \\
\hline Lung Protein:DNA & $16.8 \pm 1.9$ & $17.8 \pm 1.8$ & $16.8 \pm 1.3$ & $16.4 \pm 1.4$ \\
\hline
\end{tabular}

* The duration of exposure to air or hyperoxia was $48 \mathrm{~h}$. Vitamin $\mathrm{E}(100 \mathrm{mg} / \mathrm{kg})$ or placebo were administered subcutaneously at 1 and $24 \mathrm{~h}$ of life. Values are mean \pm SEM for number of animals listed in parenthesis.

Table 2. $\alpha$-Tocopherol content of lung tissue in newborn rabbits*

\begin{tabular}{lcccc}
\hline & $\begin{array}{c}\text { Air }+ \\
\text { placebo } \\
(n=5)\end{array}$ & $\begin{array}{c}\text { Air }+ \\
\text { vitamin E } \\
(n=7)\end{array}$ & $\begin{array}{c}\text { Hyperoxia } \\
+ \text { placebo } \\
(n=7)\end{array}$ & $\begin{array}{c}\text { Hyperoxia } \\
+ \text { vitamin } \\
\text { E } \\
(n=3)\end{array}$ \\
\hline$\alpha$-Tocopherol & 0.7 & 37.0 & 0.5 & 45.8 \\
$(\mu \mathrm{g} / \mathrm{g}$ lung $)$ & \pm 0.2 & $\pm 6.8 \dagger$ & \pm 0.1 & $\pm 8.4 \dagger$ \\
\hline
\end{tabular}

* See Table 1 footnote.

† Comparison of placebo vs vitamin E; $P<0.01$, Student's $t$ test.

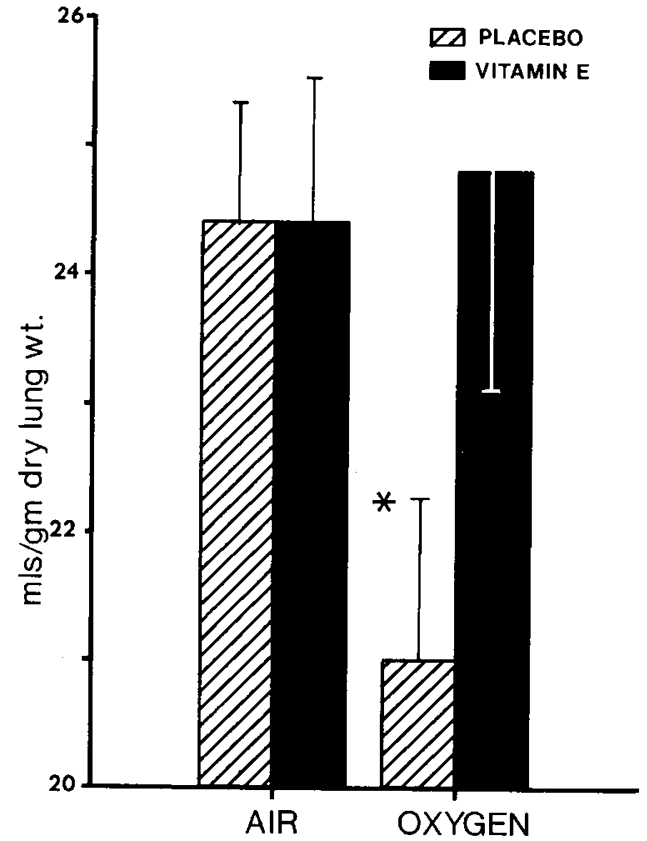

Fig. 1. Vitamin $E$ inhibition of hyperoxia-induced reduction in $V_{30}$ (maximum distensibility) in neonatal rabbits at $48 \mathrm{~h}$ of life. Bars represent mean \pm SEM for $7-13$ animals. ${ }^{*} P<0.05$, Student's $t$ test.

Lung lavage surfactant phospholipid content is illustrated in Figure 4. Exposure to hyperoxia with placebo treatment resulted in a lower content of lavage phospholipid with levels $74 \%$ of airexposed controls. In animals treated with vitamin $\mathrm{E}$ and exposed to hyperoxia, lavage phospholipid content was found to be identical to control values.

The various phospholipid components recovered by lavage were determined and are reported in Table 3. Exposure to hyperoxia did not significantly alter the relative composition of the phospholipids, although the concentration of phosphatidylglycerol was consistently lower in animals exposed to hyperoxia with placebo treatment. Comparison of animals administered vitamin $E$ with those given placebo vehicle also revealed no changes in overall phospholipid composition recovered in lavage.

Results from morphologic analysis of the four treatment groups are presented in Table 4. Determination of the relative concentrations of Type I, Type II, and undifferentiated epithelial cells revealed a statistically significant decrease in the percentage of Type I cells with a corresponding slight increase in percentage of Type II cells in hyperoxia-exposed pups given placebo. This hyperoxia effect was eliminated with vitamin $E$ tretment. In placebo-treated pups, hyperoxia exposure tended to increase capillary:interstitium ratios over air-exposed controls, but did not alter air:tissue ratios. Vitamin $E$ treatment was found to have no effect on either capillary:interstitium or air:tissue ratios. Evaluation of percentage of air spaces containing erythrocytes revealed a hyperoxia-associated increase compared with air-exposed controls. Vitamin $\mathrm{E}$ treatment abolished this hyperoxiainduced increase in percentage air spaces containing erythrocytes.

\section{DISCUSSION}

Although controversy exists with regard to the beneficial effects of vitamin $E$ ( $\alpha$-tocopherol) in newborns, studies in hyperoxiaexposed newborn animals have shown vitamin $E$ to offer protection to the lung against selected aspects of functional, biochemical, and morphologic changes associated with hyperoxia $(8,34$, 37). This report is the first to examine the effect of vitamin $E$ on the pulmonary surfactant system. In this study, vitamin $E$ was found to be effective in preventing hyperoxia-induced decrease in total airway phospholipid recovered by lung lavage.

In pressure:volume studies, animals treated with hyperoxia + placebo exhibited a right shift in the inflation phase of the pressure:volume curve (Fig. 2). This is consistent with a decrease in compliance and may reflect a compromise in surfactant function. A left shift in the deflation phase of the curve was also observed in this same treatment group. This effect may be due to air entrapment or a stiffening of lung tissue which could diminish the tendency for collapse with lowering of pressure. A similar finding in rats exposed to hyperoxia was reported with the suggestion that alveoli are "held open" as a result of hyperoxia induction of a rapid increase in lung collagen content (26). Vitamin E treatment completely abolished hyperoxia-induced decreases in pulmonary compliance and distensibility (Figs. 1, 2, 3). This finding is consistent, but may not be limited to a protection of surfactant components in the lung. This apparent protection with vitamin $E$ is consistent with a study by Wender et al. (37), who demonstrated fewer areas of atelectasis and emphysema in lung tissue of hyperoxia-exposed newborn rabbits after vitamin $\mathrm{E}$ treatment. Bucher and Roberts (8) also reported vitamin $\mathrm{E}$ reversal of hyperoxia effects on pulmonary static compliance in the neonatal rat. In this study, deflation pressure:volume curves were shifted to the right after $6 \mathrm{~d}$ of hyperoxia, in contrast to our observations of prevention of a left shift in rabbit pups after $48 \mathrm{~h}$ of hyperoxia. Additionally, vitamin $\mathrm{E}$ treatment did not inhibit maximum distensibility changes in the hyperoxia-exposed neonatal rat as reported here. These differences probably reflect the changing status of the lung according to the duration of hyperoxia exposure and the age of the animal at the time of study. Species differences may also be involved.

The amount of phospholipid recovered from the lung airspaces by saline lavage was found to be lower with hyperoxia exposure, consistent with previous time-dependent studies in the newborn rabbit (36), and reports in other species $(5,15,22,24)$. Hyperoxia 


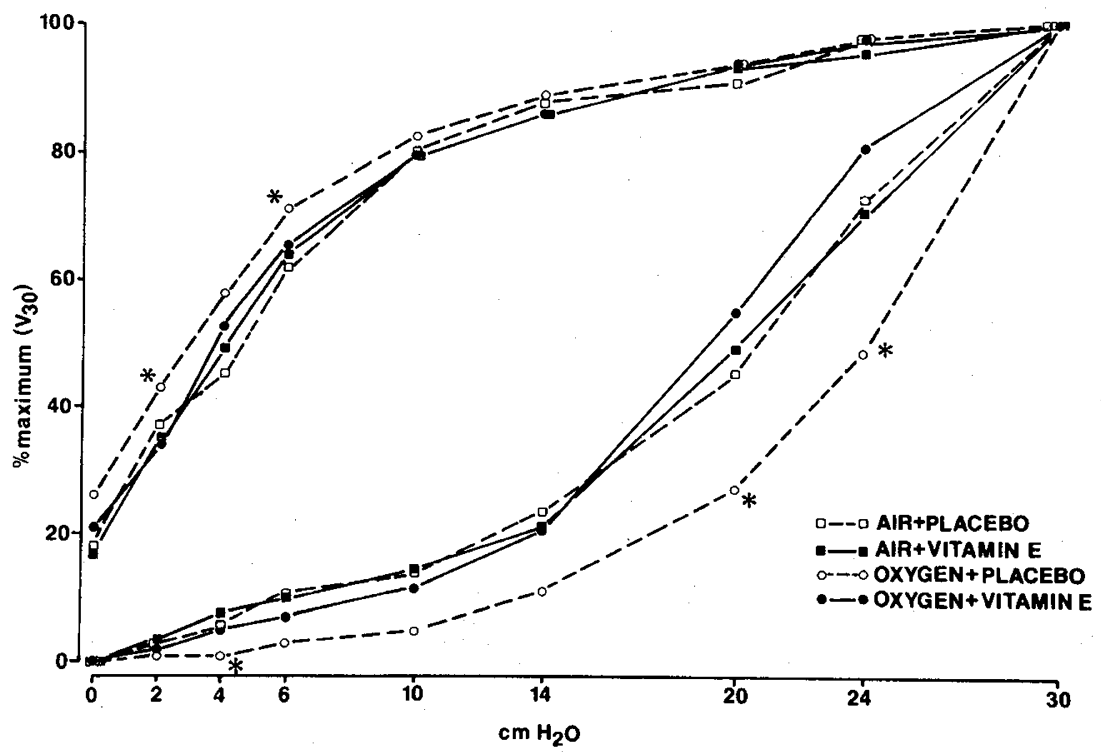

Fig. 2. Vitamin $\mathrm{E}$ inhibition of hyperoxia-induced alterations in air pressure:volume curves in neonatal rabbits at $48 \mathrm{~h}$ of life. Volume is percentage of maximum $\left(\mathrm{V}_{30}\right)$ and pressure expressed as $\mathrm{cm} \mathrm{H}_{2} \mathrm{O}$. Points represent means of $7-13$ animals. ${ }^{*} P<0.05$, Student's $t$ test.

A.

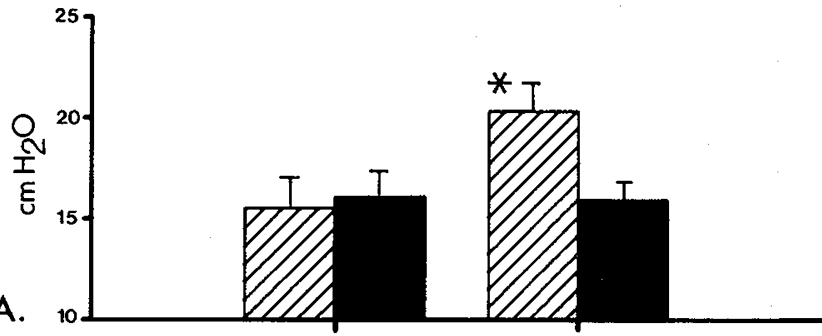

B.

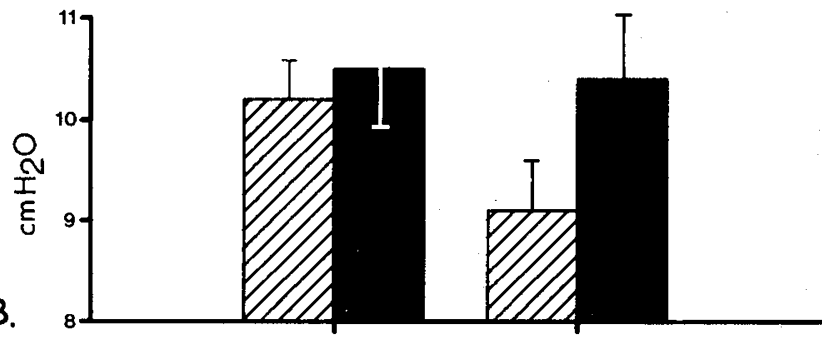

C.

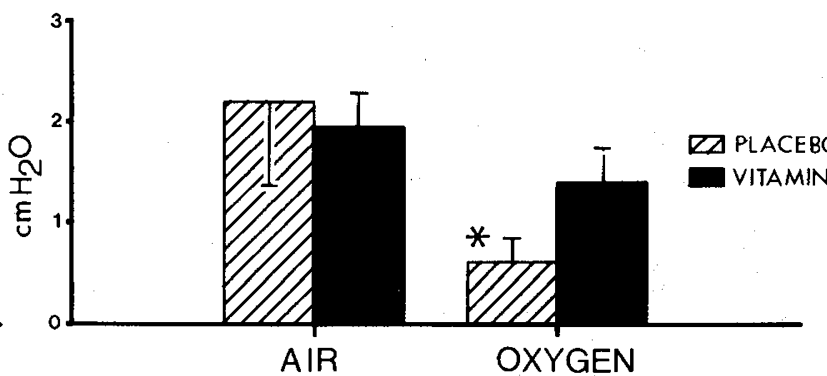

Fig. 3. Vitamin $E$ inhibition of hyperoxia-induced alterations in air pressure:volume curves in neonatal rabbits at $48 \mathrm{~h}$ of life. Data was calculated from pressure:volume curves shown in Figure 2. $(A)$ Inflation to $30 \%$ of $\mathrm{V}_{30}\left(\mathrm{P}_{30 \mathrm{i}}\right),(B)$ Deflation at $80 \%$ of $\mathrm{V}_{30}\left(\mathrm{P}_{800}\right),(C)$ Deflation at $30 \%$ of $\mathrm{V}_{30}\left(\mathrm{P}_{30 \mathrm{~d}}\right)$. Each bar represents mean \pm SEM for 7-13 animals. ${ }^{*} P<0.05$ Student's $t$ test.

toxicity is thought to occur through the generation of free radicals which are capable of inducing lipid peroxidation as well as injuring protein and DNA (11). Our observations on the effect of hyperoxia on lavage phospholipid content could involve a free radical mediated degradation of preformed phospholipid in the surfactant lining. One proposed mechanism for vitamin E pro-

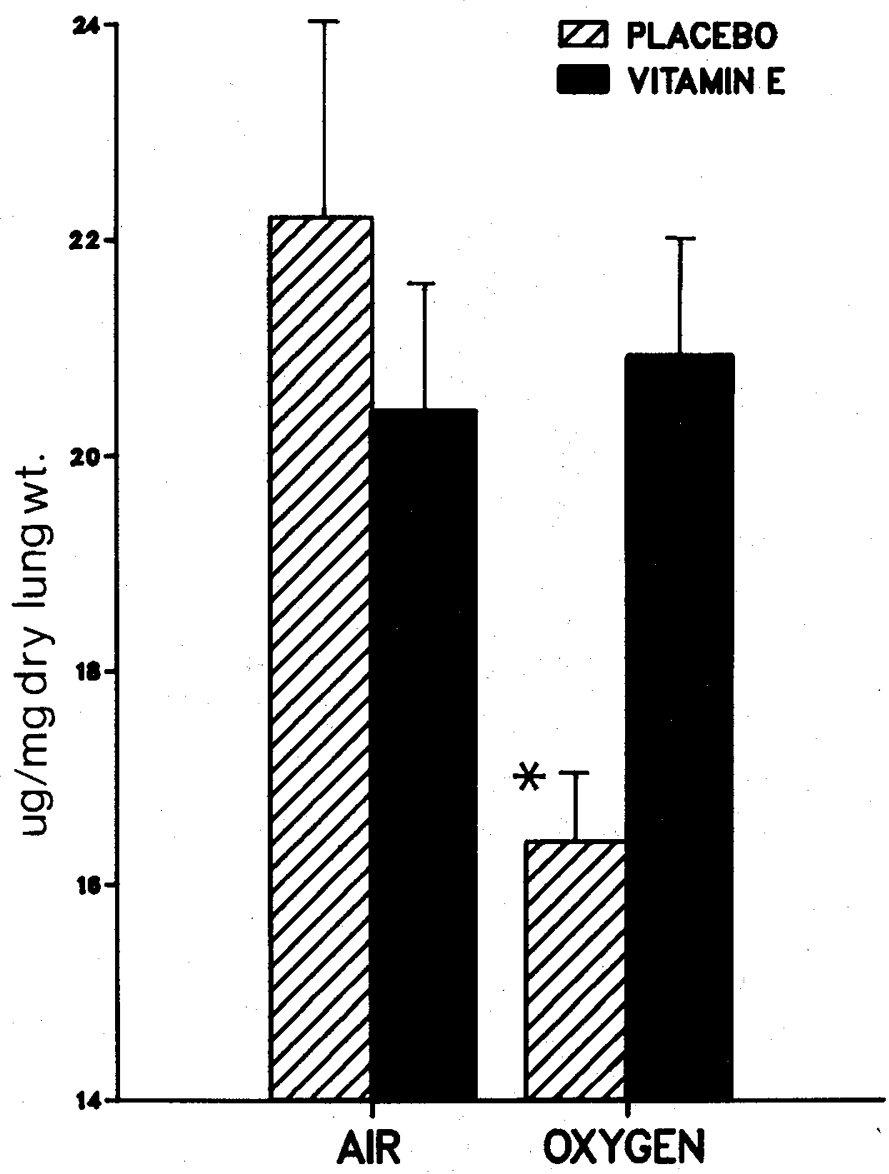

Fig. 4. Vitamin $E$ inhibition of hyperoxia-induced reduction in lung lavage phospholipid content in neonatal rabbits at $48 \mathrm{~h}$ of life. Each bar represents mean \pm SEM for $6-13$ pups. ${ }^{*} P<0.05$, Student's $t$ test.

tective action is based on its association with biological membranes and involves antioxidant protection and physical stabilization of the unsaturated fatty acid components of membrane phospholipids (20). Surfactant phospholipid is known to contain unsaturated fatty acids which are felt to have a critical role in the functional integrity of surfactant (18). Because vitamin E has been found and quantitated from lung lavage fluid extracts (14, 
Table 3. Effects of hyperoxia and vitamin E treatment on the composition of phospholipids recovered by lung lavage in newborn rabbits*

\begin{tabular}{|c|c|c|c|c|}
\hline $\begin{array}{l}\text { Phospholipid } \dagger \\
\text { (\% of total) }\end{array}$ & $\begin{array}{c}\text { Air }+ \text { placebo } \\
(n=7)\end{array}$ & $\begin{array}{l}\text { Air + vitamin } \mathrm{E} \\
\quad(n=13)\end{array}$ & $\begin{array}{l}\text { Hyperoxia }+ \text { Placebo } \\
\qquad(n=9)\end{array}$ & $\begin{array}{l}\text { Hyperoxia }+ \text { vitamin } \mathrm{E} \\
\qquad(n=10)\end{array}$ \\
\hline $\mathrm{PC}$ & $82.9 \pm 0.5$ & $82.2 \pm 1.0$ & $82.8 \pm 0.9$ & $81.9 \pm 1.4$ \\
\hline $\mathrm{PS}+\mathrm{PI}$ & $9.0 \pm 0.4$ & $8.8 \pm 0.9$ & $8.8 \pm 0.7$ & $9.5 \pm 1.0$ \\
\hline $\mathrm{PE}$ & $4.6 \pm 0.4$ & $5.4 \pm 0.3$ & $5.6 \pm 0.3$ & $5.2 \pm 0.4$ \\
\hline PG & $3.6 \pm 0.4$ & $3.7 \pm 0.3$ & $2.7 \pm 0.6$ & $3.4 \pm 0.6$ \\
\hline
\end{tabular}

* See Table 1 footnote. No significant differences were observed among treatment groups.

† Abbreviations: PC, phosphatidylcholine; PS, phosphatidylserine; PI, phosphatidylinositol; PE, phosphatidylethanolamine; and PG, phosphatidylglycerol.

Table 4. Effect of hyperoxia and vitamin E treatment on lung morphology in newborn rabbits*

\begin{tabular}{|c|c|c|c|c|}
\hline Lung morphology & Air + placebo & Air + vitamin $E$ & Hyperoxia + placebo & Hyperoxia + vitamin $\mathrm{E}$ \\
\hline \multicolumn{5}{|l|}{$\begin{array}{l}\text { Epithelial cell composition } \dagger \\
\text { (\% of total) }\end{array}$} \\
\hline Type I & $74.4 \pm 2.2$ & $71.6 \pm 1.4$ & $67.5 \pm 2.7 \ddagger$ & $70.2 \pm 1.7$ \\
\hline Undifferentiated & $12.6 \pm 2.2$ & $15.3 \pm 0.4$ & $15.0 \pm 1.8$ & $16.3 \pm 3.4$ \\
\hline Air:tissue & $4.25 \pm 0.65$ & $4.71 \pm 0.65$ & $3.94 \pm 0.33$ & $4.33 \pm 0.31$ \\
\hline Capillary:interstitium & $0.32 \pm 0.13$ & $0.47 \pm 0.08$ & $0.57 \pm 0.20$ & $0.80 \pm 0.16$ \\
\hline
\end{tabular}

* Values are mean \pm SEM for four to six animals in each treatment group.

$\dagger$ Quantitation methods described in "Materials and Methods" section.

\$ Comparison of hyperoxia + placebo $v s$ air + placebo; $P<0.05$, Student's $t$ test.

$\S$ Comparison of hyperoxia + placebo $v$ hyperoxia + vitamin E; $P<0.05$ Student's $t$ test.

$31)$, it is logical to assume that vitamin $\mathrm{E}$ could have a protective function in the extracellular surfactant lining. The quantity of vitamin $\mathrm{E}$ necessary to protect unsaturated fatty acids in surfactant would not be expected to be large because molar ratios of polyunsaturated fatty acids to vitamin E or 1000:1 are reported to provide adequate antioxidant protection in membranes (33); however, the absence of significant changes in phospholipid composition (Table 3 ) would argue against a degradation mechanism.

Alternatively, it is possible that oxygen radicals may be acting on critical processes in or on the Type II cells, resulting in impairment of surfactant phospholipid synthesis, release, and/or reuptake. According to Tappel (32), vitamin E can function nonspecifically as an antioxidant and could be expected to exert a protective action by terminating free radical reactions intracellularly including within membranes, as well as extracellularly to protect any cellular component or product. As noted previously, it has been suggested that vitamin E can specifically associate with the cell membrane to maintain stability (20). In view of the potential multiple targets of hyperoxia toxicity in the lung and the apparent vitamin $\mathrm{E}$ protection to more than one target of hyperoxia, further studies examining the effects of hyperoxia on surfactant synthesis and release, and examination of the localization and disposition of vitamin $E$ within the lung would be of value.

In addition to phospholipid analysis, we evaluated the lung morphometrically to determine whether vitamin E exerted any action on the concentration of the Type II cells in the alveolar walls of hyperoxia-exposed animals, as well as to determine whether the lung tissue in general was protected from hyperoxia injury. The morphologic evidence of pulmonary oxygen toxicity observed in our newborn rabbit studies followed the pattern of response reported in the newborn rat and in many adult species $(6,9)$. Effects of hyperoxia exposure for $48-72 \mathrm{~h}$ as described by Kistler et al. (19) in the adult rat included pulmonary edema, increased interstitial thickness, and swelling of the capillary endothelium and alveolar epithelium. Changes in the epithelial cell composition reported by Crapo et al. (10) reflect proliferation of Type II cells in compensation for injured or lost Type I cells.
Results of this study are in agreement with this pattern of hyperoxia toxicity. Vitamin $\mathrm{E}$ appeared to act selectively in protecting against changes in cell-type composition in the lung parenchyma, and inhibiting hyperoxia-associated increase in erythrocytes present in air spaces, but offered no protection against increased capillary:interstitial ratios. Hansen et al. (16) measured vascular permeability and lung water in hyperoxiaexposed newborn lambs and also reported no protective effect of vitamin $\mathrm{E}$ on these parameters.

Previous evaluations of vitamin $E$ protection against hyperoxia toxicity in the lung have yielded conflicting results $(7,12,13,16$, $21,29,37)$. There are several possible explanations for this apparent inconsistency. The parameters utilized to assess the status of the lung (physiologic, biochemical, morphometric) have varied and are not equally affected by hyperoxia $(6,9)$. Vitamin E may protect against only selected components of hyperoxiainduced lung injury, such as the surfactant system; thus, it may be critical to examine the lung with a comprehensive approach in order to clearly understand the protective role of vitamin $\mathrm{E}$. Another possible source of difference is the timing of both hyperoxia exposure and vitamin $E$ treatment. Because the amount of surfactant recovered by lavage increases as much as 10-fold with air breathing in the first hours of life (28), hyperoxia exposure could compromise the release of surfactant into the airway. For maximal effectiveness, vitamin $\mathrm{E}$ treatment would have to be initiated at the onset of oxygen exposure and breathing. It is also known that the lung's response to hyperoxia progresses from an exudative phase to a proliferative phase with continued exposure (11). It is possible that vitamin E exerts a protective action only in the first stage of oxygen toxicity. Clinical studies which have failed to observe the protective effect of vitamin $E$ may have included infants affected by oxygen exposure before having achieved adequate lung tissue levels of vitamin $E$. Finally, baseline vitamin E status, nutritional supplementation with vitamin $\mathrm{E}$, and route of administration, dose and dosage form of vitamin $E$ are all factors which may influence the response of subjects to pharmacologic doses of vitamin E. It appears likely that vitamin $E$ treatment which corrects a vitamin E deficiency state benefits the lung, but once adequate threshold 
levels of vitamin $\mathrm{E}$ are achieved nutritionally, no further protection can be provided even with pharmacologic doses (8). In the study reported herein, rabbit pups were found to be vitamin $\mathrm{E}$ "deficient," i.e., levels of vitamin $\mathrm{E}$ in lung were $25 \%$ of those observed in pups of the same age allowed to suckle $(0.7 \pm 0.2$ $\mu \mathrm{g} / \mathrm{g}$ versus $2.6 \pm 0.7 \mu \mathrm{g} / \mathrm{g}$, respectively). The artificially-fed model can thus be considered to be appropriate in relation to the human premature neonate who often receives a parenteral or otherwise artificial nutritional regimen which contains levels of vitamin $E$ less than that found in colostrum $(7,8)$.

In conclusion, the findings reported herein suggest that early vitamin $\mathrm{E}$ therapy in newborns exposed to hyperoxia is effective in preventing hyperoxia-associated compromise in the pulmonary surfactant system. In view of the critical importance of achieving adequate surfactant in newborns receiving oxygen support for respiratory distress syndrome, further studies evaluating the mechanism of action of vitamin $E$ on the surfactant system, including the design of optimal vitamin $E$ treatment regimens are indicated.

\section{REFERENCES AND NOTES}

1. Abbasi, S., Johnson, L., and Boggs, T.: Effect of vitamin $E$ by infusion in sick small premature infants at risk for BPD. Pediatr. Res., I4: 638 (1980).

2. Albro, P. W.: Determination of protein in preparations of microsomes. Anal. Biochem., 64: 485 (1975).

3. Bartlett, G. R.: Phosphorus assay in column chromatography. J. Biol. Chem., 243(3): 466 (1959).

4. Bligh, E. G. and Dyer, W. J.: A rapid method of total lipid extraction and purification. Can. J. Biochem. Physiol., 37(8): 911 (1959).

5. Brashear, R. E. and Christian, J. C.: Endobronchial lavage phospholipids and protein in rats protected from oxygen toxicity by hypoxia pretreatment. Metabolism, 22(11): 1345 (1973).

6. Bucher, J. R. and Roberts, R. J.: The development of the newborn rat lung in hyperoxia: a dose-response study of lung growth, maturation, and changes in antioxidant enzyme activities. Pediatr. Res., 15: 999 (1981).

7. Bucher, J. R. and Roberts, R. J.: $\alpha$-Tocopherol (vitamin E) content of lung, liver, and blood in the newborn rat and human infant: influence of hyperoxia. J. Pediatr., 98(5): 806 (1981).

8. Bucher, J. R. and Roberts, R. J.: Effects of $\alpha$-tocopherol treatment on newborn rat lung development and injury in hyperoxia. Pediatr. Pharmacol. 2: 1 (1982).

9. Clark, J. M. and Lambertsen, C. J.: Pulmonary oxygen toxicity: a review. Pharmacol. Rev., 23(2): 37 (1971).

10. Crapo, J. D., Peters-Golden, M., Marsh-Salin, J., and Shelburne, J. S.: Pathologic changes in the lungs of oxygen-adapted rats: a morphometric analysis. Lab. Invest., 39(6): 640 (1978).

11. Deneke, S. M. and Fanburg, B. L.: Normobaric oxygen toxicity of the lung. N. Engl. J. Med., 303: 76 (1980)

12. Ehrenkranz, R. A., Ablow, R. C., and Warshaw, J. B.: Prevention of bronchopulmonary dysplasia with vitamin $\mathrm{E}$ administration during the acute stages of respiratory distress syndrome. J. Pediatr. 85:873 (1979).

13. Ehrenkranz, R. A., Bonta, B. W., Ablow, R. C., and Warshaw, J. B.: Amelioration of bronchopulmonary dysplasia after vitamin $\mathrm{E}$ administration. $\mathrm{N}$. Engl. J. Med., 299: 564 (1978).

14. Farrell, P. M.: Vitamin E deficiency in premature infants. J. Pediatr., 95(5): 869 (1979).

15. Gross, N. J. and Smith, D. M.: Impaired surfactant phospholipid metabolism in hyperoxic mouse lungs. J. Appl. Physiol.: Respir. Environ. Exer. Physiol., 5I(5): 1198 (1981)

16. Hansen, T. E., Hazinski, T. A., and Bland, R. D.: Vitamin E does not prevent oxygen-induced lung injury in newborn lambs. Pediatr. Res., 16: 583 (1982).

17. Khosla, S. S., Smith, G. J. W., Parks, P. A., and Rooney, S. A.: Effects of estrogen on fetal rabbit lung maturation: Morphological and biochemical studies. Pediatr. Res., 15: 1274 (1981).
18. King, R. J., and Clements, J. A.: Surface active materials from dog lung. II. Composition and physiological correlations. Am. J. Physiol., 223(3): 715 (1972).

19. Kistler, G. S., Caldwell, P. R. B., and Weibel, E. R.: Development of fine structural damage to alveolar and capillary lining cells in oxygen-poisoned rat lung. J. Cell Biol., 32: 605 (1967).

20. Lucy, J. A.: Functional and structural aspects of biological membranes: a suggested structural role for vitamin $E$ in the control of membrane permeability and stability. Ann. N. Y. Acad. Sci., 203: 4 (1972).

21. McClung, H. J., Backes, C., Lavin, A., and Kerzner, B.: Prospective evaluation of vitamin $E$ therapy in premature infants with hyaline membrane disease. Pediatr. Res., 14: 604 (1980).

22. Morgan, T. E., Finley, T. N., Huber, G. L., and Fialkow, H.: Alterations in pulmonary surface active lipids during exposure to increased oxygen tension. J. Clin. Invest., 44(II): 1737 (1965).

23. Northway, W. H., Rosan, R. C., and Porter, D. Y.: Pulmonary disease following respiration therapy of hyaline-membrane disease: Bronchopulmonary dysplasia. N. Engl. J. Med., 276: 357 (1967).

24. Redding, R. A., Arai, T., Douglas, W. H. J., Tsurutani, H., and Overs, J.: Early changes in lung of rats exposed to $70 \% \mathrm{O}_{2}$. J. Appl. Physiol., 38(1): 136 (1975).

25. Richards, G. M.: Modifications of the diphenylamine reaction giving increased sensitivity and simplicity in the estimation of DNA. Anal. Biochem., 57:369 (1974).

26. Riley, D. J., Berg, R. A., Edelman, N. H., and Prockop, D. J.: Prevention of collagen deposition following pulmonary oxygen toxicity in the rat by Cis4-hydroxy-1-proline. J. Clin. Invest., 65: 643 (1980).

27. Rooney, S. A., Wai-Lee, T. S., Gobran, L., and Motoyama, E. K.: Phospholipid content, composition and biosynthesis during fetal lung development in the rabbit. Biochim. Biophys. Acta, $431: 447$ (1976).

28. Rooney, S. A. and Gobran, L. I.: Alveolar lavage and lavaged lung tissue phosphatidylcholine composition during fetal rabbit development. Lipids, 12(12): 1050 (1977)

29. Saldanha, R. L., Cepeda, E. E., and Poland, R. L.: The effect of vitamin E prophylaxis on the incidence and severity of bronchopulmonary dysplasia. J. Pediatr., 101(I): 89 (1982).

30. Schacterle, G. R. and Polack, R. L.: A simplified method for the quantitative assay of small amounts of protein in biological material. Anal. Biochem., 51: 654 (1973).

31. Tangney, C. C.: Vitamin $E$ levels in lung, plasma, and bronchoalveolar (B/A) lavage fluids in rabbits and man. Fed. Proc., 41(3): 345 (1982).

32. Tappel, A. L.: Vitamin E as the biological lipid antioxidant. Vitam. Horm., 20: 493 (1962).

33. Tappel, A. L.: Lipid peroxidation damage to cell components. Fed. Proc., 32(8): 1870 (1973).

34. Taylor, D. W.: The effects of vitamin $E$ and of methylene blue on the manifestations of oxygen poisoning in the rat. J. Physiol., 131: 200 (1956).

35. Ward, J. A. and Roberts, R. J.: Use of the newborn rabbit as a model for the evaluation of lung development. Pharmacologist, 22(3): 250 (1980).

36. Ward, J. A. and Roberts, R. J.: Hyperoxia effects on pulmonary pressure: volume characteristics and lavage surfactant phospholipid in the newborn rabbit. Biol. Neonate (in press), 1984.

37. Wender, D. F., Thulin, G. E., Smith, G. J. W., and Warshaw, J. B.: Vitamin $\mathrm{E}$ affects lung biochemical and morphologic response to hyperoxia on the newborn rabbit. Pediatr. Res., 15: 262 (1981).

38. Westerberg, E., Friberg, M., and Akesson, B.: Assay of brain tocopherols using high performance liquid chromatography. J. Liquid Chromatogr., 4(1): 109 (1981).

39. The authors would like to thank Ms. Mary Jo Kline and Mr. Jack Burke for expert technical assistance, Ms. Denise Morrell for preparation of the manuscript, and Dr. W. E. Scott and Hoffmann-LaRoche, Inc., for supplying $\alpha$ tocopherol.

40. Requests for reprints should be addressed to: Dr. Robert J. Roberts, Departments of Pediatrics, The University of lowa College of Medicine, Iowa City, IA 52242

41. This research was supported by U. S. Public Health Training Grant \#GM07069 and Research Grant \#GM12675.

42. Received for publication August 26, 1982.

43. Accepted for publication July 5, 1983. 